\title{
Are Degree-awarding Institutions doing enough to Support the Implementation of Quality Assurance in Transnational Higher Education Partnerships?
}

Claudia M. Bordogna ${ }^{l}$

The Centre of People, Work and Organisational Practice, Nottingham Business School, Nottingham Trent University.

Abstract: As transnational education grows in complexity, it is imperative degreeawarding institutions develop ways to ensure the quality of their offshore provision. Whilst agencies, such as the QAA in the UK and TEQSA in Australia, safeguard standards through guidelines and reviews, it is vital degree-awarding institutions consider their own actions in the pursuit of academic quality. Although codes of conduct can guide quality assurance, this paper suggests these documents are not enough to ensure quality education occurs. Offering a study of two Chinese-British transnational partnerships, this paper identifies two key challenges that can affect the implementation of quality assurance at the operational level: time and cultural difference. The findings suggest that senior managers at degree-awarding institutions should consider how their structures and policies encourage and support the implementation of quality assurance at the operational level.

Keywords: Transnational higher education partnerships, quality assurance, assessment, operational academic staff, codes of conduct.

\section{Introduction}

Globalisation and its impact on the process of internationalisation has become increasingly important to the higher education (HE) sector (Knight, 2003). For many Higher Education Institutions (HEIs), internationalisation has enabled them to create and implement a series of international activities such as study abroad initiatives, the recruitment of international students and staff, and the transportation of educational services to other countries through transnational education arrangements (Knight, 2003). Transnational higher education (TNE) refers to programmes where students themselves do not move across borders, but instead remain in their home country, whilst following an educational programme delivered by a foreign provider or agency (McNamara \& Knight, 2015).

In principle, TNE has created a new market for HEIs. Students who are unable to travel for financial, cultural, or political reasons, can access education within their own countries. Moreover, it provides host countries with access to higher education resources and increased absorptive capacity, whilst at the same time enabling them to develop their own educational infrastructures and capacity (Gow, 2007). Although TNE arrangements can vary from international branch campus, franchise, validation, and 'flying faculty' modes of delivery, many often require one or more stakeholders to forge partnerships with

\footnotetext{
${ }^{1}$ The Centre of People, Work and Organisational Practice, Nottingham Business School, Nottingham Trent University, Nottingham, UK. Email: claudia.bordogna@ntu.ac.uk
} 
overseas representatives (Knight, 2015). In doing so, the degree-awarding institution is often reliant on local contacts implementing, supporting, and delivering their educational programme to a set academic standard, which is comparable to the experience of students studying at the campus of the degree-awarding institution (QAA, 2010).

According to academics Harvey and Green (1993), quality has always been an important higher education issue, yet the pursuit of quality is not easy. HEIs must ensure their services are "“exceptional', perfect...consistent...fit for purpose... and "transformative"” (Harvey \& Green, 1993, p. 11, original emphasis). Furthermore, 'quality' comprises of aspects such as 'control, assurance, management, audit, assessment, policy and funding' (Harvey \& Green, 1993, p.10). In a TNE context, one may argue that maintaining and monitoring quality is even more arduous, since it involves a series of duediligence tasks. These range from the identification of appropriate models for delivery, the sourcing and evaluating of partners and the negotiation of agreements; to more operational focused activities, including the managing of cultural differences, expectations, curricula and assessments (Helms, 2015; Henderson, Barnett \& Barnett, 2017). It is vital therefore, that stakeholders charged with the management of TNE at partner institutions, understand their responsibilities and take ownership of their TNE service, so quality is continuously monitored and maintained.

Although incumbent on the degree-awarding body to assess the risks involved and manage these appropriately, in the UK, the Quality Assurance Agency (QAA) offers additional support and guidance on how to manage the risk and threats inherent in overseas activities (QAA, 2010). However, whilst these code of practice and guidance documents provide frameworks and safeguarding measures for the Higher Education sector, the QAA clearly consider it the responsibility of the degree-awarding institution to manage 'academic standards and quality of learning delivered on its behalf, wherever it takes place' (QAA, 2010, p.3).

To ensure quality prevails, degree-awarding institutions cannot simply rely on the distribution of a series of codified instructions to relevant operational academic staff members, both home and overseas, in the hope that quality standards will ensue. On the contrary, quality codes do not always appreciate the environmental or social factors that make the implementation of these guidelines complex (Smith, 2010). As Hodson and Thomas (2001) suggest, codes of practice 'have created systems that lack cultural sensitivity' (p.102), arguably rendering the implementation of some quality indicators problematic. For example, the creation of 'common understandings of graduate standards 
and the meaning of quality', 'performance indicators' and the use of 'peer reviewing' and assessment criteria, established in one cultural setting, may be subject to different interpretations, judgement and possible 'manipulation when applied in other cultural settings' (Hodson \& Thomas, 2001, p.104-105). Codes of practice, whilst useful in guiding quality, do not ensure quality. Quality services are facilitated through a process of continuous engagement, dialogue, evaluation and reconfiguration of strategic and operational environments and processes (Houston \& Paewai, 2013).

This paper aims to contribute to discourse focused on TNE operational management, with a specific focus on the implementation of quality assurance (QA) standards. To do this, it utilises a qualitative methodology, whereby the subjective experiences of operational academic staff members are explored, to ascertain their thoughts on their degree-awarding institution and its role in the implementation of QA standards. First, to understand how this research was conducted, it is important to clarify what is meant by the term ' $Q A$ ' in this context. Although numerous TNE, offshore or collaborative code of practice documents exist, since this particular study involved two Chinese-British research cases, it made sense to refer to the document that all British HEIs involved in collaborative provision are expected to refer to. This study therefore, specifically used the QAA's (2017) UK Quality Code for Higher Education: Part B Assuring and Enhancing Academic Quality. Chapter B10: Managing HE Provision with Others as a reference tool for what was meant by the term 'QA'.

\section{Defining 'quality assurance':}

The section of Chapter B10 referring to 'quality assurance' contains five indicators. These indicators explicitly relate to the arrangements degree-awarding bodies should put in place to ensure 'the maintenance of academic standards and the quality of the learning opportunities provided' (QAA, 2017, p.27). Each indicator in the section refers to a specific aspect of QA. For example, indicator 13 covers 'module and programme approval'; indicator 14, 'admitting and registering students'; indicator 15, 'assessment requirements'; indicator 16, 'external examining procedures' and finally, indicator 17 covers the monitoring and reviewing of modules and programmes (QAA, 2017, p. 27-32).

For the purposes of this research, it was deemed impossible to analyse findings in relation to all five indicators and offer a comprehensive analysis herein. Therefore, one indicator was identified to be of specific interest: 
Indicator 15: Degree-awarding bodies ensure that delivery organisations involved in the assessment of students understand and follow the assessment requirements approved by the degree-awarding body for the components or programmes being assessed in order to maintain its academic standards. In the case of joint, dual/ double awards... degree-awarding bodies agree with their partners on the division of assessment responsibilities and the assessment regulations and requirements which apply (QAA, 2017, p.29).

The rationale for choosing indicator 15 was based on the assumption that all operational academic staff members interviewed for this study would have experience of assessing teaching and learning activities, over some of the other indicators, which may require a more senior level or administrative involvement. Moreover, as Pyvis (2011) explains, cross-border assessments are often problematic for QA; foreign assessment formats and terminology can cause challenges for overseas tutors implementing the assessments, and the academics at the degree-awarding institution creating them.

The paper proceeds by first exploring literary sources that investigate quality and TNE, and the role played by HEIs in relation to QA and academic staff. Riad Shams (2017) argues that academic staff are often overlooked and undervalued in the design and implementation of QA frameworks by their HEI. Whilst their professionalism is integral and instrumental in ensuring QA processes and practices prevail, HEIs do not always provide appropriate structures and policies to ensure this is the case. Although this research provides interesting insights into the level of faculty member engagement in QA within HEIs, paucity exists when it comes to understanding the challenges inherent in offshore delivery that can influence the implementation of QA at the operational level. This research, therefore, seeks to enhance our understanding of the challenges that surround academic staff members when trying to implement QA (indicator 15) in TNE contexts. By listening to the voices of academics tasked in the delivery of transnational programmes, this paper aims to recommend ways in which degree-awarding institutions can strengthen their structures and policies to ensure QA is continuously maintained and evaluated at the operational level.

\section{TNE, quality assurance and academic staff:}

There is a plethora of studies that examine quality in HE and TNE (e.g. Hodson \& Thomas, 2001; Coleman, 2003; Cheung, 2006; Kettunen 2011), thereby evidencing the importance of the research focused on this phenomenon. Many address the role played by 
non-governmental and government QA agencies (Stella, 2006; Woodhouse, 2006; Smith, 2010) in regulating and protecting the quality of educational services (Riad Shams, 2017). Clearly, these external authorities, such as the UK's QAA, Australia's TEQSA, or decentralised registered assurance agencies in Germany, such as ACQUIN or AQAS, who are responsible to the German Accreditation Council, have been instrumental in driving improvements in QA processes in HE. However, when it comes to TNE, supranational agencies, such as UNESCO and the OECD, also play a part in the QA process (OECD, 2005). Whilst many of these documents emphasize the need for 'control and surveillance' (Houston, 2010, p. 179), few pay attention to educational theory, processes, or student learning (Harvey, 2002). Houston (2010) contends that whilst QA frameworks contribute to the management and regulation of quality in $\mathrm{HE}$, many of the mechanisms listed fail to address the core functions of teaching and research. He argues that academic staff members tasked in the delivery of these functions are largely bypassed when changes to QA process are developed.

Other studies concur that QA discussions overlook how human interactions produce the foundations that make quality education possible (Houston \& Paewai, 2013). This is problematic, because the success of many quality initiatives depends on the dedication of the academic unit or department, and the support provided to them (Hénard, 2010). Furthermore, since TNE is a service that requires acute and responsive operational management, due to the large amounts of cooperation, translating of knowledge and sharing of resources required between operational academic staff members (Watty, 2003), it seems that a critical component concerning the implementation of QA is being overlooked and undervalued by researchers, agencies and educational institutions. Consequently, it seems many staff members, regardless of whether they are involved in offshore provision, are not consulted by their HEIs when it comes to the design and implementation of QA systems (Houston \& Paewai, 2013).

Due to the complex nature of TNE, Henderson, Barnett and Barrett (2017) argue that there is an increasing demand for knowledgeable and experienced staff, who can plan and manage the 'increasingly complex operational and academic requirements of TNE successfully and to ensure quality' (p.14). Academic staff, both at home and overseas, who are responsible for managing TNE provision are now expected to deal with aligning the strategic objectives of multiple institutions, project management, and the protection of academic standards and reputations, all whilst creating equitable and comparable student learning experiences (Pyvis, 2011). Clearly, the complex activities associated with TNE 
operations should be of serious concern to stakeholders within degree-awarding bodies who are responsible for ensuring the quality of a TNE provision. It seems pertinent therefore, to offer a contribution towards assisting these stakeholders in understanding how they can devise structures and systems to support operational academic staff members in the pursuit of QA. However, little research exists that investigates this matter. Whilst Henderson, Barnett and Barrett (2017) identify activities associated with ensuring successful TNE delivery, this merely represents one side of the operational coin. The other side, being knowledge of how to create systems that support QA within TNE contexts.

Watty (2006) suggests that to understand quality in higher education, institutional leaders and policy makers should seek the advice of both academics and students who best understand the conditions that create quality education. Issues affecting the implementation of QA in the delivery of TNE, range from the implementation of equivalent curricula and assessment, to the use of comparable administrative systems and student support mechanisms (Lim, Bentley, Henderson, Pan, Balakrishnan, Balasingam, \& Ya Yee Teh, 2016). Lim (2010) suggests that a lack of understanding by top management as to what is involved in the delivery of offshore education causes tensions, whereby those designing institutional QA processes and those tasked with their implementation are seemingly worlds apart.

Certainly, QA regulatory documents, toolkits, and institutional responses require academic staff members to read, digest, and implement as prescribed. However, if staff members feel there is dissidence between guideline meanings, institutional processes and applicability in practice, then it is possible they may struggle to apply the recommendations (Edwards, Crosling \& Edwards, 2010), creating what Newton (2000) describes as prompted ritual responses, or performances of compliance. Should degreeawarding institutions try to understand some of the challenges facing operational academic staff members in the implementation of QA in TNE environments, and create appropriate supportive structures and policies, there is hope that more meaningful and less superficial forms of staff engagement will transpire.

It seems, from an analysis of literary sources, that there is consensus surrounding the important role academic staff members play in the delivery of quality higher education, whether it is transnationally operated or not. Previous research suggests that academic relationships and operational tasks underpin QA and are fundamental in ensuring exceptional, consistent, and equitable education occurs (Pyvis, 2011; Houston \& Paewai, 2013; Riad Shams, 2017). In the context of TNE, there is a limited amount of research 
existing that informs us of how degree-awarding bodies and their structures and policies affects the way operational academic staff members experience and implement QA in TNE programmes. The remainder of the paper will demonstrate, through an empirical study of operational academic's subjective experiences, how awarding institutions can better understand operational challenges to improve the implementation of QA standards.

\section{Methodology}

Table 1 shows the composition of the two Chinese-British partnership cases analysed for the purposes of this study. All partnerships operated at the same host institution in a major city in China. The host institution is an international university college established as a joint venture between a Chinese University and UK partners, who are predominantly Post 1992 institutions (a former polytechnic given university status through the UK Further and Higher Education Act 1992). Partnerships A and B both ran business programmes, and ran a similar combination of TNE activities in the delivery of their programmes, including articulation (year one), franchise (year two) and 'fly-in-fly-out' (year three).

\begin{tabular}{|c|c|c|c|c|c|c|}
\hline $\begin{array}{l}\text { Chinese } \\
\text { Institution }\end{array}$ & $\begin{array}{l}\text { UK } \\
\text { Institution }\end{array}$ & Partnership & Discipline & $\begin{array}{l}\text { Partnership } \\
\text { Duration }\end{array}$ & $\begin{array}{l}\text { China-based } \\
\text { Academic Members }\end{array}$ & $\begin{array}{l}\text { UK Academic } \\
\text { Members }\end{array}$ \\
\hline \multirow[t]{2}{*}{$\begin{array}{l}\text { X } \\
\text { (Single } \\
\text { institution in } \\
\text { China) }\end{array}$} & A & $(\mathrm{X}$ and $) \mathrm{A}$ & $\begin{array}{l}\text { Business } \\
\text { (Management) }\end{array}$ & 6 years & $\begin{array}{l}\text { China-based A } \\
1 \text { course leader Tom } \\
\text { (American) } \\
2 \text { local academics } \\
\text { Hannah }(\text { French), } \\
\text { Eliza }(\text { Swedish) }\end{array}$ & $\begin{array}{l}\text { UK A } \\
1 \text { course leader Ann } \\
\text { (British) } \\
2 \text { module leaders Louise } \\
\text { (British), Keith (British) }\end{array}$ \\
\hline & B & (X and) B & $\begin{array}{l}\text { Business } \\
\text { (Finance) }\end{array}$ & 6 years & $\begin{array}{l}\text { China-based B } \\
1 \text { course leader David } \\
\text { (Canadian) } \\
2 \text { local academics } \\
\text { Sally (British), } \\
\text { Charles (British) }\end{array}$ & $\begin{array}{l}\text { UK B } \\
1 \text { course leader Lidia } \\
\text { (British) } \\
2 \text { module leaders } \\
\text { Rob }(\text { British), Claire } \\
(\text { British) }\end{array}$ \\
\hline
\end{tabular}

Table 1: Case configuration

Access to the sample was gained through the researcher's TNE network and comprised of 'operational academic staff members' (either programme leaders, course leaders, module leaders, or local tutors) who were involved in the operational (teaching and learning) delivery of their programme. All faculty working in China were expatriates from either Europe, Canada, or the USA. Only a small number of academic staff members worked on their TNE partnerships on behalf of their institutions. Therefore, whilst participant numbers seem low, the participation rates as a percentage were $100 \%$ of academic members from partnership A and 75\% for partnership B. The configuration of each case and participant pseudonyms are shown in table 1. 
All participants were given a project outline and attended a semi-structured interview lasting between 60-90 minutes. BERA (2011) ethical protocols were applied, and consent given by all participants. The interview questions sought to understand their roles, teaching and learning responsibilities, daily challenges and activities. All interviews were conducted in English, transcribed and coded using a method for thematically analysing qualitative data, known as template analysis (King, 2012). Initially, the transcripts were coded based on descriptive, low inference codes, before inferential pattern codes were used to pull together material into smaller and more meaningful units.

Furthermore, the researcher retained a high level of reflexivity during the research process, whereby the reflective remark sheets of Miles and Huberman (1994, p.66) were used to capture any initial thoughts and observations during data collection.

Data analysis identified a range of challenges that seemed to influence the delivery of TNE programmes, for example, poor inter- and intra- team relations, inadequate communication and limited access to resources. However, when it came to assessment practices and QA, two key themes repeatedly emerged as being significant to staff members: time and cultural difference. The remainder of this paper therefore, analyses and evaluates these two factors in relation to the implementation of indicator 15 (QAA, 2017).

\section{Findings and Discussions}

\section{Factor 1: Time}

A key factor that was frequently mentioned by all participants in relation to TNE assessment practices was time. Hannah (China-based A) described the challenge of working on a UK programme within a Chinese academic calendar, whereby conflicting holiday times, such Chinese New Year, Christmas and Easter, often meant she felt unable to contact UK A for support in the management of assessments:

I felt lost sometimes and alone...I had an issue with one student who was in hospital and she needed an extension. I really needed confirmation, but there was no one in the UK. Should I make the decision on my own? Would it be correct? I really need confirmation from [name]. (Hannah)

Eliza (China-based A) concurred, suggesting that when the UK were "absent" she felt "unsure as to how to deal with certain issues", fearing the possible "repercussions" of her decisions. 
$\operatorname{Rob}(U K B)$ further discussed how a lack of time to engage in meaningful conversations with his overseas tutor about assessment practices created unnecessary problems. Describing an assessment issue that arose concerning the production of "model student exam answers", he maintained that only by having time to discuss these issues "clearly and calmly" and "understand the surrounding circumstances" could you hope to "stop problems like this in the future". Claire $(U K B)$ agreed that time is fundamental when trying to resolve assessment issues:

I feel our time's getting you know, tighter and tighter and squeezed and squeezed and squeezed. I used to think I had time to have these conversations around assessment and feedback and discuss things to prevent issues arising again, but no. (Claire, UK B)

Keith (UK A), having worked at host institute $X$ prior to joining UK A, believed that an "eight-hour time delay" had "big- knock on effects" in terms of organising assessments. For example, he mentioned how his local tutor, Eliza (China-based A), had emailed requesting the "reopening of an assessment link,", and recalled being "away at the time at a conference". To him, these issues caused "unnecessary delays and stress", whereby he suggested that his home institution was partially to blame, since it imposed "superiority and dominance" in the management of the programme. He argued that to improve relations, more responsibility should be given to China-based A colleagues in terms of 'the division of assessment responsibilities' (QAA, 2017, p.29). Although he maintained "ultimate responsibility still needs to reside with the degree-awarding institution".

Tom (China-based A), referred to one absolute degree-awarding institutional policy that he felt caused tensions between his team and UK A. He described how a UK mandate regarding the "turnaround of assessments in three weeks", regardless of student numbers, was impossible to honour:

You must have it done in three weeks, end of story. If a paper takes thirty minutes to mark, you do the maths and the work hours. I have other modules... it's actually impossible to manage properly. (Tom)

Ann, Louise and Keith all concurred that this policy, which is an absolute UK institutional requirement, put "increased pressures on all academic staff, regardless of their involvement in a TNE programme" (Ann, $U K A)$, limiting meaningful engagement in 
assessment and feedback. Claire ( $U K B$ ) agreed, describing how absolute institutional policies at her UK institution affected academic integrity and decision-making processes:

[I]'m not saying we lose our academic integrity or anything, but I think more staff make decisions on what's pragmatic...I mean this year we all got sent an institution wide email saying that if we didn't have our marks in by the deadline set, they would consider disciplinary action. A blanket threat. So, I have a problem with my partner's marks, it's going to take time to sort, but I may get disciplinary action? And they insist on academic integrity? So, you just think "oh bollocks to it, I'm just getting my marks in on time". (Claire)

Both Sally and Charles (China-based B) believed that a general lack of support from their own Chinese HEI made the delivery of their TNE programme even more challenging:

Time is a factor. Everyone is so busy in their roles you know, there's so much to do these days, academic roles have expanded and expanded, making it harder to focus and prioritise key tasks... and senior management don't quite know what's involved. (Sally)

Senior management expect us to do so many hours...this does affect us and the quality of the work we are producing, last year we adapted, but this year it is overwhelming because of large student numbers. (Charles)

This sentiment was also echoed by UK participants:

Our [Awarding HEI] just see the money and they think "oh they're alright, we'll leave them to get on with it", I don't know. Even when it went really, really bad last year, nobody was there for us, people in Registry were very negative towards us. (Louise, UK A)

The above findings suggest that:

1) A lack of appreciation of the work and time involved in the managing of TNE programmes by both host and degree-awarding institutions is a significant factor in reducing the ability of academic staff to identify, discuss, and tackle assessment violations. 2) That conflicting academic calendars can often leave local academics feeling vulnerable and unsupported by their UK partner. Moreover, local tutors seem to feel uncomfortable in taking ownership of assessment processes when UK staff are unavailable to validate their decisions. 
Degree-awarding bodies should therefore, consider developing contingency plans to cover TNE academic staff who are absent, perhaps coupled with a reduction in the level of micromanagement to empower local academics to take ownership of certain assessment processes. 3) That absolute policies decreed by degree-awarding institutions can negatively affect all academic staff in the production of quality assessment and feedback. All these points have serious ramifications for the maintenance of indicator 15 in relation to 'academic standards' (QAA, 2017, p.29).

Furthermore, these three points imply that the implementation of indicator 15 is reliant on more than simply following 'the assessment requirements approved by the degree-awarding body' (QAA, 2017, p.29). To enable the implementation of indicator 15, degree-awarding institutions need to spend time understanding the operational complexities of TNE and how these can be managed to enable better assessment practices, whilst simultaneously educating their host institution on ways to strengthen their operational teams in the delivery of academic standards (QAA, 2010). For example, a perceived shortage of time, created by having multiple academic responsibilities, coupled with the need to meet absolute institutional policies, such as set deadlines, is acknowledged by all staff as being instrumental in reducing the quality of assessment and feedback. By examining degree-awarding and host academic staff workloads, it may be possible to reduce or redeploy duties, enabling staff to spend more time on assessment tasks, thus meeting absolute deadlines (if these are non-negotiable). Additionally, a consideration of protocols to cover degree-awarding staff when on annual leave, may also offer relief to offshore academic staff.

\section{Factor 2: Cultural difference}

A reoccurring theme throughout all the transcripts was that of cultural difference and its effects on assessment practices. This resonates with the findings of Sharp (2017), whereby he identifies the challenges of ensuring academic standards and quality learning experiences occur across different cultural contexts. Chinese and British socio-cultural differences create deep-rooted histories, which generate conditions that affect the production and outputs of TNE activities. Academic staff working in TNE are clearly trying to span and reconcile cultural, social, psychological, political, and economic divides, whilst at the same time searching for common ground on which to establish shared meanings. In both partnerships, all academic staff made some reference to cultural differences and the implications for assessment. 
In the case of partnership A, Keith (UKA) contended that China-based A colleagues followed their own agendas, engaging in tasks not in keeping with UK processes. To him, this was because China-based A colleagues did not "identify with the UK" or see themselves as part of "our [UK] institution", creating a "misalignment between the two groups". Moreover, he clearly recognised how "differences in agendas and values" meant teaching activities, such as assessment and feedback, might have "not meet the expectations of either partner group". Ann $(U K A)$ further explained why she felt this happens:

We have completely different sets of standards and expectations...that's where the variables come in, because of the level of expectation that we have, we expect China to behave in a certain way and they don't! (Ann)

To highlight these cultural difficulties, UK A recall a specific event which nearly caused the partnership to collapse. Ann explained how an event referred to herein as "Examinationgate" caused her to become suspicious of China-based A colleagues, when 135 year 2 students recorded a high level of achievement across all exams:

$[\mathrm{M}] \mathrm{y}$ perception was that the student marks were inflated because they [Chinabased A colleagues] wanted the students to get a good grade, but we knew these students were not capable...it might be a quick fix for the student, but in the bigger picture it wasn't... we put the brakes on. (Ann)

Louise (UKA) also referred to "Examinationgate", and how she felt it evidenced the cultural differences apparent between China-based A colleagues and UK A. According to Louise, the difference in motives created a "stalemate" which highlighted the different approaches and requirements of both the UK and Chinese educational systems:

[T] hey were trying to create a table of statistics, they were trying to create statistics that they had been told to produce...the students we had couldn't achieve those statistics, so that's where the issue came...they've got to meet the statistics, but you can't make a silk purse out of a sow's ear... you can't throw it all out of the window, and go “oh well, I'll tell you what, we'll give them that mark anyway, $\mathrm{f}^{* * *}$ it", you can't do that and that's why, because we're coming at it from two different perspectives, there was a gap. (Louise) 
Keith (UK A), using his experiences of working in China, shared his thoughts on why this problem arose:

In China to get into university it's a process you go through. At the end of four years you come out, you've been through the process and you get your degree, it's a completely different value set, so when you look at our partnership, those two things are mixed. The Chinese partners push students through, will accept lower standards because they don't fail...you're stuck in limbo because we have standards, but the Chinese are not always reaching those standards. (Keith)

Eliza (China-based A) was the only China-based academic who seemingly agreed with certain aspects of this. She felt her Chinese institution was only "interested in low failure rates, as opposed to the UK, who are more interested in quality as opposed to quantity", and had insinuated that this cultural difference perhaps "had not helped the situation", in relation to "Examinationgate".

"Examinationgate" suggests that even though the degree-awarding institution can set assessment requirements and criteria, there may be other underpinning mechanisms that influence the maintenance of academic standards. Through an evaluation of this assessment activity, it can be argued that QA guidelines, such as indicator 15, cannot account for, or stop tasks being reinterpreted to suit cultural preferences. Hannah (Chinabased A) supports this sentiment, when she stated:

Our system is not British you know. I remember reading some regulations and mark schemes and everybody interpreting them in a different way, I understood one thing, her another...it's the interpretation, the "word". It is not perhaps the same for us? (Hannah)

Partnership B also identified similar issues. Although 'the assessment requirements approved by the degree-awarding body' (QAA, 2017, p.29) had been established by Rob $(U K B)$, he described a time when he was teaching in China, and was left perplexed as to why his local tutor had failed to use the agreed mark scheme correctly:

It was just not marked clearly, I had to challenge that person. I don't know why it wasn't realised. Marks had been totally missed so they all had to be remarked...He also had to write a resit exam paper and it was just dreadful. That had to be 
redone, and they had five years of past papers to consult! I can never understand why he didn't get it right, but he didn't and I have to accept that. (Rob)

Claire $(U K B)$ also referred to a time where assessments were set, but not followed correctly:

We sat down and covered the exam and how we planned to mark it, we all sat down and did that, so we got really disappointed when they were marked in a completely different way...we did not agree the marks. (Claire)

Lidia (UK B) further described feeling "baffled" as to why certain assessment protocols were not followed correctly. She explained how she often "wondered why it happened in that way", as $\operatorname{did} \operatorname{Rob}(U K B)$. Yet she felt that the requirement to meet absolute institutional deadlines, coupled with a lack of institutional support, whereby she felt her institution needed to take "more responsibility for the quality...do more in terms of quality checks", was a key reason quality declined. Charles (China-based B) validated this interpretation, when he noted that "the UK didn't really fulfil their responsibilities in checking and vetting, that was very evident, we need greater communication and it has improved". Claire suggested that "although no one gets an easy ride" there was a fear in her institution that by "questioning, we are sort of saying, you lot are cheats!", with no senior management seemingly wanting to take responsibility for the problem.

With no factual and proven understanding as to why assessment problems occurred, both UK A and UK B blame cultural differences as their underpinning rationale. Differences in the Chinese and UK educational systems were cited, including the Chinese skill of "rote learning materials" or "copying as a sign of respect", "government statistical requirements", a "focus on high pass rates" and "quantity over quality". It can be argued that a weakness in QA guidelines in this context, is its inability to guide degree-awarding institutions on the way cultural variations could impede the implementation of QA. This is not to suggest code of practice documents thereby contain reams of cultural information, after all, the QAA already offers numerous quality reviews of TNE that specifically refer to a range of countries, including China (QAA, 2013), Greece and Cyprus, India and the Caribbean (QAA, n.d). Whilst all these documents contain positive features and recommendations, what is not mentioned, and shared so openly, by degree-awarding bodies are the cultural challenges they face when trying to implement QA, and ways in which these challenges were resolved. Problems constitute a taboo subject that if 
mentioned, could seemingly implicate and label numerous degree-awarding bodies as failing to uphold and deliver QA. Clearly no institution wishes to have this label, but equally no institution is without problems. In this context, it was clear that UK academic staff members felt unsupported by their degree-awarding institution, in that no senior support was offered to defend the decision-making processes of staff facing serious breaches of assessment protocols.

\section{Conclusions}

This paper does not claim that its depictions of QA at the operational level, or degreeawarding absolute polices are generalizable to other TNE enterprises. On the contrary, a limitation of this study is that it focuses on two specific UK TNE partnerships based at a single Chinese institution, and its conclusions and recommendations are therefore, contextually situated. Nevertheless, it does provide insights into the challenges that face both home and overseas operational staff members when trying to implement QA. Although the QA indicator 15 used in this study originates from a UK QAA guidance document, it is noted that many- if not all- international quality agencies refer to the importance of quality in assessment and feedback practices (INQAAHE, n.d). Consequently, this study prompts its audience to reflect upon the QA issues presented herein. It asks stakeholders, who are contemplating or currently engaged in TNE, to consider how two factors, inherent in overseas operations, time and cultural difference, are being scrutinized and monitored within their degree-awarding institution.

Findings from this study suggest that ensuring quality indicators are adhered too is a challenge at the operational level. Whilst the QAA $(2010,2017)$ make no suggestion that managing international programmes is straightforward, this research serves to highlight how complex it is to manage QA in transnational contexts. Although codes of practice documents can guide quality assurance practices, this paper suggests that this is not enough to ensure QA is implemented at the operational level. All operational academics who participated in this study seemingly understood the 'assessment requirements approved by the degree-awarding body' and their 'assessment responsibilities' (QAA, 2017, p.29). Yet, issues still arose in the completion of assessment tasks. Ergo, it seems that guidance alone is not enough to ensure QA is successfully implemented and maintained. 


\section{Managerial Implications}

This paper recommends senior executives at degree-awarding institutions consider how time and cultural difference may affect assessment processes and be vigilant for signs of these negatively infiltrating QA. In a recent study by Sharp (2017), he argues that cultural contexts can create "misunderstandings" in how regulatory practices relating to academic standards and quality are interpreted and executed. He contends that learning preferences and cognitive styles are influenced by cultural contexts, meaning “"quality' in this sense must always be seen as context-dependent" (p.151).

This paper agrees with this sentiment, arguing that there must be a better appreciation of cultural difference, and how it influences the practices of all academic staff members operating TNE programmes. Clearly, academic staff members on both sides of the partnership need to be encouraged by their respective HEI to discuss operational issues that concern QA. Yet, this will only occur if academic members feel supported by senior management at their HEI in having these sensitive conversations. This paper suggests that degree-awarding institutions actively support and defend staff who wish to question TNE QA processes. By encouraging staff members to openly voice their concerns, in a safe supportive environment, it may serve to improve and enhance QA in their offshore operations. For example, operational staff members may wish to discuss the affect certain absolute institutional policies are having on the management of their overseas operations, or they may wish to discuss resourcing issues, assessment violations or suspicious teaching practices on a module. Finally, degree-awarding institutions should consider other ways to support and enhance QA at the operational level. For example, by ensuring all academic staff are conversant in assessment requirements and institutional protocols, ideally through routine reviews and training, further enhanced by visits to overseas partners (Pyvis, 2011) and/or participation in discussion forums (Raid Shams, 2017).

\section{References}

BERA. (2011). Ethical Guidelines for Educational Research. London: BERA.

Coleman, D. (2003). Quality assurance in transnational education. Journal of Studies in International Education, 7(4), 354-378.

Edwards, J., Crosling, G., \& Edwards, R. (2010). Outsourcing university degrees: Implications for quality control. Journal of Higher Education Policy and Management, 32(3), 303-315. 
Gow, I. (2007). Removing the rose-tinted spectacles. In A. Fazackerley \& P. Worthington (Eds.), British Universities in China: The Reality Beyond the Rhetoric. An Agora Discussion Paper (pp. 8-10). London: AGORA: The Forum for Culture and Education. Harvey, L., \& Green, D. (1993). Defining quality. Assessment \& Evaluation in Higher Education, 18(1), 9-34.

Harvey, L. (2002). Evaluation for what? Teaching in Higher Education, 7(3), 245-263. Helms, R. M. (2015). International Higher Education Partnerships: A Global Review of Standards and Practices. Washington D.C: American Council on Education (ACE). Hénard, F. (2010). Learning Our Lessons: Review of Quality Teaching in Higher Education. OECD and Institutional Management in Higher Education. Retrieved 23rd November, 2017, from

https://www.oecd.org/edu/imhe/learningourlessonreviewofqualityteachinginhighereducatio $\underline{\text { n.htm }}$

Henderson, M., Barnett, R., \& Barrett, H. (2017). New developments in transnational education and the challenges for higher education professional staff. Perspective: Policy and Practice in Higher Education, 21(1), 11-19.

Hodson, P. J., \& Thomas, H. G. (2001). Higher education as an international commodity: ensuring quality in partnerships. Assessment \& Evaluation in Higher Education, 26(2), 101-112.

Houston, D. (2010). Achievements and consequences of two decades of quality assurance in higher education: A personal view from the edge. Quality in Higher Education, 16(2), 177-180.

Houston, D., \& Paewai, S. (2013). Knowledge, power and meanings shaping quality assurance in higher education: A systematic critique. Quality in Higher Education, 19(3), 261-282.

INQAAHE. (n.d.). The International Network for Quality Assurance Agencies in Higher Education retrieved $10^{\text {th }}$ January, 2018, from http://www.inqaahe.org/full-members-list Kettunen, J. (2011). External and internal quality audits in higher education. The TQM Journal, 24(6), 518-528.

Knight, J. (2015). International universities: Misunderstandings and emerging models? Journal of Studies in International Education, 19(2), 107-121.

Knight, J. (2003). Updated Definition of Internationalization. International Higher Education, 33, 2-3. 
King, N. (2012). Using templates in the thematic analysis of text. In C. Cassell \& G. Symon (Eds.), Essential Guide to Qualitative Methods in Organisational Research (3rd ed., pp. 254-270). London: Sage Publications.

Lim, F.C.B. (2010), "Do too many rights make a wrong? A qualitative study of the experiences of a sample of Malaysian and Singapore private higher education providers in transnational quality assurance", Quality in Higher Education, 16(3), 211-222.

Lim, C. B., Bentley, D., Henderson, F., Pan, S. Y., Balakrishnan, D. V., Balasingam, D. M., \& Ya Yee Teh. (2016). "Equivalent or not? Beyond measuring teaching and learning standards in a transnational education environment". Quality Assurance in Education, 24(4), 528-540.

McNamara, J., \& Knight, J. (2015). Transnational Education Data Collection Systems: Awareness, Analysis, Action. Retrieved $1^{\text {st }}$ June, 2015, from

http://www.britishcouncil.org/sites/britishcouncil.uk2/files/1.1_report_tne_data_collection system.pdf

Miles, M. B., \& Huberman, A. M. (1994). An Expanded Sourcebook: Qualitative Data Analysis (2nd ed.). London: Sage Publications.

Newton, J. (2000). Feeding the beast or improving quality? Academics' perceptions of quality assurance and quality monitoring. Quality in Higher Education, 6(2), 153-163. OECD. (2005). Guidelines for Quality Provision in Cross-border Higher Education. Paris, France: OECD.

Pyvis, D. (2011). The need for context- sensitive measures of educational quality in transnational higher education. Teaching in Higher Education, 16(6), 733-744.

QAA. (2010). Code of Practice for the Assurance of Academic Quality and Standards in Higher Education: Collaborative Provision and Flexible and Distributed Learning (October 2010 ed.). Gloucester: QAA.

QAA. (2013). Review of UK Transnational Education in China 2012. Gloucester: QAA. QAA. (2017). UK Quality Code for Higher Education Part B: Assuring and Enhancing Academic Quality. Chapter B10: Managing Higher Education Provision with Others. Gloucester: The Quality Assurance Agency.

QAA (n.d.). Review of Transnational Education. Retrieved $9^{\text {th }}$ January, 2017, from http://www.qaa.ac.uk/reviews-and-reports/how-we-review-higher-education/review-ofoverseas-provision

Riad Shams, S. M. (2017). Transnational education and total quality management: A stakeholder-centred model. Journal of Management Development, 36(3), 376-389. 
Sharp, K. (2017). The distinction between academic standards and quality: Implications for transnational higher education. Quality in Higher Education, 23(2), 138-152.

Smith, K. (2010). Assuring quality in transnational higher education: A matter of collaboration or control? Studies in Higher Education, 35(7), 793-806.

Stella, A. (2006). Quality assurance of cross-border higher education. Quality in Higher Education, 12(3), 257-276.

Watty, K. (2003). When will academics learn about quality? Quality in Higher Education, 9(3), 213-212.

Watty, K. (2006). Want to know about quality in higher education? Ask an academic.

Quality in Higher Education, 12(3), 291-301.

Woodhouse, D. (2006). The quality of transnational education: A provider view. Quality in Higher Education, 12(3), 277-281. 